\title{
The Relationship of Consumer Attitude and Government Regulations Towards Online Gambling Behavior in The Philippines
}

\author{
Alexis Devera Lamoste ${ }^{1}$, Yuliana Riana Prasetyawati ${ }^{2}$ \\ 1,2 Institut Komunikasi dan Bisnis LSPR, Jakarta, Indonesia
}

\begin{abstract}
The Philippine gambling industry, and particularly online gaming, has recently emerged as a major driver of the country's economy. The rise of this controversial industry has become a cause of concern for many Filipino citizens. For the past two decades, Business Process Outsourcing (BPO) has been a major driver of the Philippine economy. However, a new sector of the economy has emerged that appears poised to take over traditional BPOs: online gambling. With the emergence of online gambling, any citizen can simply log into a website and they can play the usual casino games like poker, roulette, and slot machines or even sports betting. Online gambling is just like having a wallet in your pocket right now and just waiting for the money to come in, you just pull out your cellphone and you gamble already right away, that easy. Technically, engaging in online gambling is legal unless operated by a Philippine-licensed offshore company. Unlike other countries, the Philippines does not have strict mandates against gambling. The research aims to cover if consumer attitude and government regulations are significantly proportion with the effect of online gambling behavior. Adding to that, the researcher has added an intervening variable which is promotional ads if it has a direct impact adopting online gambling behavior. By using a quantitative analysis, the study recorded 100 respondents residing in the Philippines and studying their opinion towards this new addictive behavior relating to money. The materials and resources collected have concluded that consumer attitude and government regulations have significant impact towards this unlikely behavior, while promotional ads remain irrelevant.
\end{abstract}

KEYWORDS

Online Gambling, Government Regulations, Philippines

\section{INTRODUCTION}

It has been said that life is one big gamble. Sooner or later, a person has to make a very important decision in his life, and he must weigh his options carefully. His success depends on making the right decision. That's a gamble because much of the future is uncertain, something like what happens in the gambling world. Gambling is considered as one of the fastest way to earn money. It's been so heavily marketed and normalized and available in different shapes and forms - it's everywhere. Gambling is an activity that involves any betting or wagering, for self or others, whether for money or not, no 
matter how slight or insignificant, where the outcome is uncertain or depends on chance or skill (Gamblers Anonymous, 2000; McCormick \& Cohen, 2007). Led by casino's and slot machines, there are more and more types of gambling products that are widely spread with the success of their marketing campaign.

Figure 1. Roman-era dice

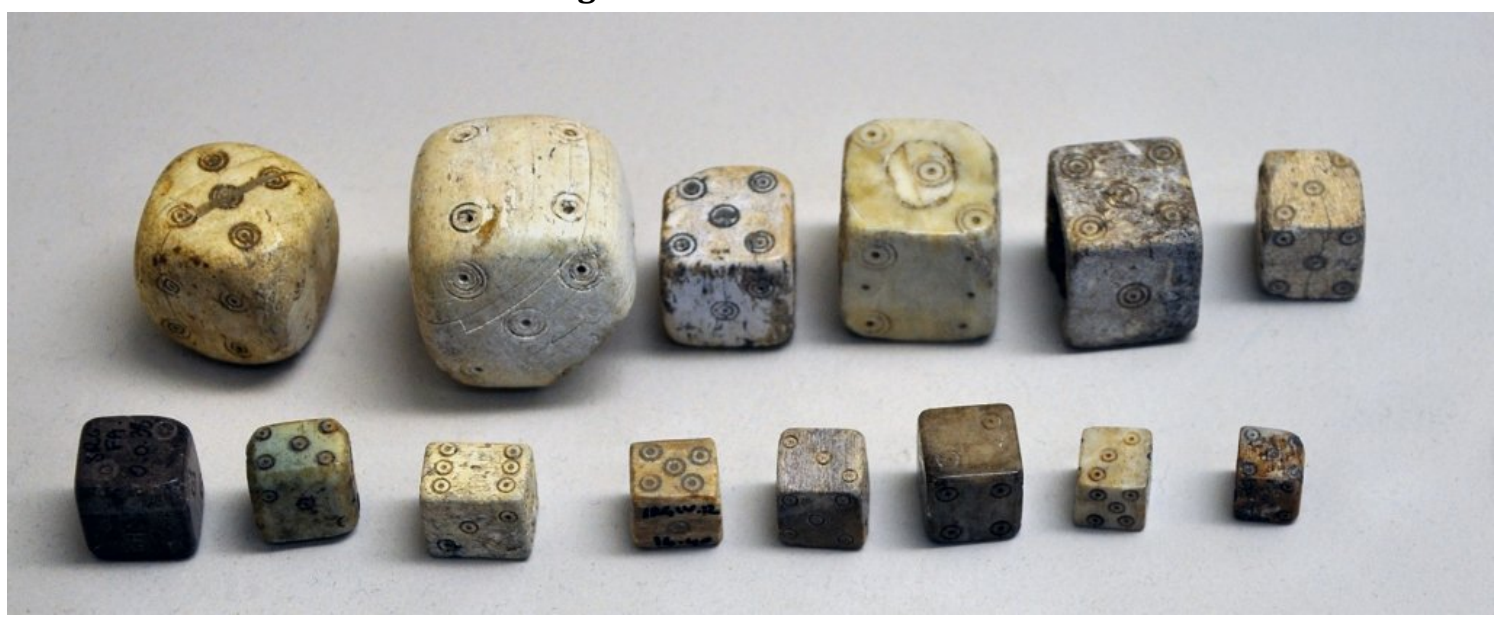

Source: (Science Alert, 2018)

There have been some beliefs that some form of gambling and game of chance have always been present since the early period. Researchers have discovered the first cubeshaped dice dating back to $3000 \mathrm{BC}$ and something called astragalomancy, which used the dice as a tool to predict the future and spiritual certain truths. By $500 \mathrm{BC}$ dice games and other forms of gambling had become all the rage in Greek, Roman and Egyptian culture. However, the government in Rome wasn't exactly behind this trend and imposed strict fines for anyone caught gambling. Citizens were so active on playing that they came up with the idea for gambling chips as they started playing with fake money and players could later settle their debts, therefore authorities couldn't penalize them. According to (Starr, 2018),

Roman-era dice, the researchers found, were a mess when it came to shape. They were made from a variety of materials, such as metal, bone and clay, and no two were shaped entirely alike. Many were visibly lumpy and lopsided, with the 1 and 6 on opposite sides that were more likely to roll up.

Over the decades, China continued to invent new games and gambling only increased in popularity. Gambling houses were everywhere and provided a source of entertainment that people couldn't seem to resist. Early versions of modern gambling are believed to be active as early as 14 th century. The first version of games that are still being played today began to appear across Europe. Baccarat is the earliest recorded game that you can play in casinos across the world today. This two player game certainly evolved over the centuries as it made its way from Italy, France and Britain to Cuba and finally to the US. Up until today, this game is well known in light of the fact that it includes high stakes 
and makes for a great spectator sport. Guests can cheer on the player as they try to beat the bank and win huge pots. While China had been home to gambling houses for centuries and games of chance were played in the streets and homes of people across the world, what is considered the first casino opened its doors in 1638 in Italy. The term Casino has Italian origins and roughly translates to summerhouse or social club. The Ridotto introduced to the public or referred to as a "Private room" where gambling is present. The name came from the Italian word "ridurre", which means "to force" or "to reduce". It was established by the Italian to try and regulate and to provide a controlled gambling environment. However, due to its high stakes and formal dress code, only nobles could afford to play at the casino's tables.

As time goes by and together with the advancement of technology, gambling has hit some major milestones. Gambling began to represent a real big business when casinos started to be attended also by less wealthy classes. Sabbadin (2017) supported that gambling was in fact considered both as an entertainment for nobles and as way to challenge the fate for poorer people, in order to increase their living condition and their status.

Back in 1700's, the first roulette wheel appeared in Paris, while in 1800's, the modern version of poker began being played in New Orleans and eventually found its way to Las Vegas. Around 1970's, poker tournaments started becoming more popular and eventually transformed into the highly competitive game it is today. Slot machines was also a part of history as it was introduced in 1970's. In the U.S, gambling became legal in the state of Nevada as early as 1930's serving the city of Las Vegas to be the Mecca of gambling. However, the United States decided to legalize gambling on some states due to The Great Depression around 1970's. Goodman (1995) added that because Las Vegas held a monopoly on casino gambling for such a long time, it was able to reap the benefits of tourists who spent their money in the city's casinos, hotels, restaurants, and shops.

Once seen as illegal, immoral, or disreputable, gambling is often seen today as a form of recreation and, at times, even as a source of income. Forms of gambling have a common core - the chance of winning something of greater value than the amount staked - but differ in terms of structural characteristics (Parke, Parke, \& Blaszczynski, 2016). Further clarification is helpful in understanding how gambling activities are defined in different situations. Commercial gambling advertising is everywhere - in magazines, bus shelters, subways, and on radio, television, and the internet. The prevalence of these ads assures that youth will be exposed to them, and may have an effect on early gambling experiences (Skinner, Biscope, Murray, Korn, 2004). Commercial Gambling is a formal, regulated style of gambling that includes a variety of gambling types such as casinos, video lottery terminals, lottery tickets, horse racing, and legal sports betting, among others. Commercial gambling is characterized by an unequal relationship between the gambling provider and the gamblers: as a group, the gamblers always lose 
money to the provider. Private gambling depends your chance of winning or losing through chances and skills. It includes betting on card games such as poker among friends, or betting on sports results with colleagues at the office, unlike commercial gambling, money is redistributed within the group. Recreational gambling is gambling for leisure, recreation, or entertainment purposes and in low-risk and/or controlled situations. Often times these gamblers are called social gamblers do not tend to incur lasting life problems from gambling. The five most common motivations among recreational gamblers were found to be winning, exploration, excitement, being with friends and being with similar people (Platz \& Millar, 2001). Illegal gambling represents yet another group of gambling activities. Popular forms of illegal gambling, such as bookmaking on sports and horse races, underground casinos, and numbers running. Like commercial gambling, illegal gambling is characterized by an unequal relationship between providers and players. Unlike commercial gambling, illegal gambling providers are not constrained by laws or regulations to pay winners or to collect debts through legitimate avenues.

\section{Innovation of Gambling}

The Internet has expanded into-and in some cases, reshaped-almost every realm of modern life. Gambling is no different, when public and commercial use of the Internet began in early and mid-1990s, it soon became apparent that this could also be a medium used for gambling. Throughout the years gambling has evolved heavily and has been innovated parallel to technology which can now be accessed by the use of mobile phones. European Commission (2011) stated that the current proliferation of Internet gambling and other platforms, such as mobile devices, smartphones, tablets, and Internet protocol television, among other devices, has also raised the awareness of public policy makers and other gambling-related stakeholders, who have further expressed concern regarding the difficulty in controlling and/or surveying Internet gambling. When asked about advantages of gambling on the Internet versus gambling in land-based venues, Internet gamblers typically cite accessibility and convenient access (Gainsbury, Wood, Russell, Hing, \& Blaszczynski, 2012). Being highly demanded to several countries, gambling has had its fair share in terms of their revenue. Internet gambling sites remain widely accessible and promisingly profitable. Online gambling is about betting some entry, usually money based on the result of the played game. As can be realized from its name, the user plays the game online. There are different types of online gambling. Some of them include online Poker, slots, online casino, lotteries, sports betting and other kind of games. With the development of technology and access to the internet, the popularity of online gaming also increased. To conclude, the technology of today makes gambling possible from almost any location, ranging from the bedroom to the bathroom and even outdoors. 
Figure 2: Gross Gaming Revenue

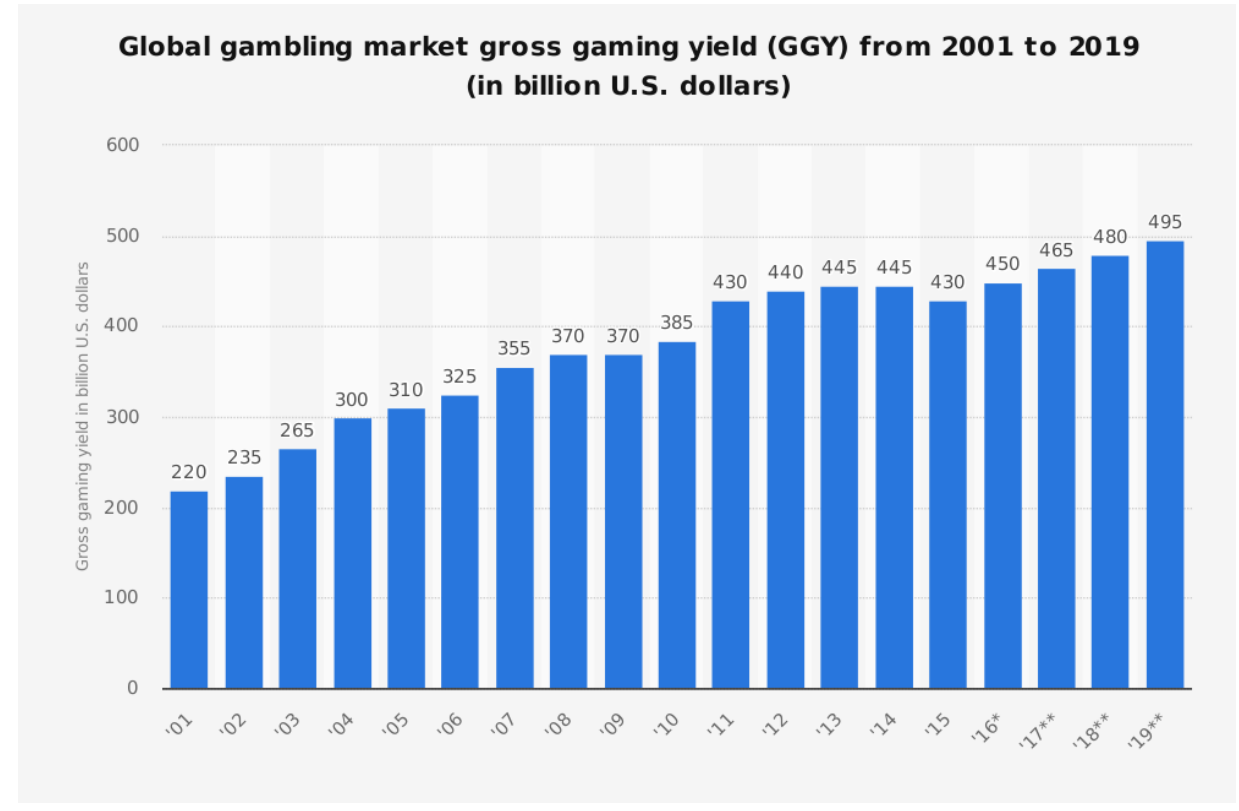

Source: Statista, 2020

Statista (2020) have provided the latest Gross Gaming Yield until 2019. GGY simply means the income after its payout to the customers or players. Gross gambling yield does not take into consideration the costs of the business - staff wages, restaurant and bar stock, advertising and similar expenses. It is the total of all money paid to the casino or online betting by players as bets, minus the payout made to those players as winnings. The high internet penetration and increasing use of mobile phones among individuals for playing online games from their homes and public places are driving the market. In addition, factors such as easy access to online gambling, legalization and cultural approval, corporate sponsorships, and celebrity endorsements are also contributing to market growth.

According to Bridget Sand (2017) -- chair IAGR trustee and patron:

Globally, the legal age to gamble follows the age of majority, but with a wider range of permitted ages (16 to 25 ) across jurisdictions and markets. With respect to foreign investment (in betting and land-based/online casinos) there are no restrictions in most jurisdictions (59\%).

\section{Gambling in the Philippines}

The South-East Asian cluster of islands known as the Philippines are now one of the region's most popular destinations for gambling. Gambling is very big in the Philippines which makes it a very interesting and relatively new market for online gambling and starting to look like a formidable rival to the nearby gambling tourist trap of Macau. Gambling in the Philippines is generally restricted by government laws. Historically, Sabong (cock fighting) has been a popular past-time in the Philippines, with both legal and illegal matches taking place on a regular basis - fans can gamble on the legal events using a number of specialist websites licensed by distinct regions. Though online 
gambling is legal in the Philippines, most of the advertisements can only be seen inside the casino or at hotels. Sponsoring certain events is one way of promoting online gaming websites in the Philippines. These sponsors are greatly active during big sporting events. Then there are private promotions that include sending emails to random people by giving them bonuses \& marketing promotions that would led Filipinos fall prey to the online gambling market. Online gambling became such a popular market in the Philippines in a short period of time. There are no laws prohibiting online gambling in particular, therefore legal.

According to ASEAN Briefing (2017),

The Philippines has two distinct regions where it handles all online gambling activities. The Philippine Amusement and Gaming Corporation (PAGCOR) control the majority of the Philippines where gambling is controlled by the Government owned PAGCOR. PAGCOR operates their land-based casinos, and betting outlets across the country. The second region is the Cagayan Economic Zone Authority (CEZA) and Freeport which most people just call "Cagayan Freeport." This is based mainly at the Manila Entertainment Complex next to Manila Bay. This is the only area in the Philippines not under complete control of PAGCOR.

The Philippine Amusement and Gaming Corporation (PAGCOR) and First Cagayan Resort and Leisure corporation oversees all gambling activity in the country. These agencies were put into place to help combat illegal gambling activities as well as promote a safe experience for players in the area. The law does not simultaneously make it a crime for Filipino players to place bets online, hence players are free to engage in legal online casino gambling from offshore gambling sites. Gambling business is attached to PAGCOR and is the only organization franchised by the government to utilize casinos within the country. Majority of its services consist of table games and slot machines. Nowadays It also offers internet gaming, internet sports betting, and bingo and slot machine demo units.

Internationally recognized games like Baccarat, Black Jack, Roulette, Craps, Big \& Small, Pai Gow Poker, Stud Poker, Pontoon, and Super 6 are available in its Casino Filipino branches. Alongside with table games and slot machines, PAGCOR has also expanded its operations to include the conduct and regulation of bingo games as it expands the image of Casino Filipino from a gaming venue into a wholesome entertainment for the whole family.

With the gambling industry in the Philippines currently flourishing, it is not outside the realm of possibilities that the laws may evolve to expand the online gambling opportunities within the island region, however, there have not been any moves in this direction thus far. While the Philippine Amusement and Gaming Corporation (Pagcor) prohibits offshore gaming licenses from offering services and allowing access to Filipinos, unlicensed gambling websites from other countries are just as accessible as 
other regular websites. Finding these online gambling websites have become easy for Filipinos nowadays as they can just do a simple research on internet and look for companies allowing Philippines to access and play on their gambling websites. Hundreds of gaming sites are available on the internet, amplified by advertisements that draw people of all ages to try and gamble. Tech Addiction (n.d.) expressed that Gambling is no exception and is just another activity that no longer requires a trip outside one's residence. Today, gamblers can play blackjack, poker, slots, roulette, and any other game of chance from the comfort of their own homes.

Attitude of Filipinos towards gambling is very much the same to other countries. Filipinos rely on the chance of winning little to huge amounts more often. Losing their bets won't hold them back from playing, in fact, most Filipinos will be anxious to retrieve their losses without realizing how much money have been wasted. Online gambling has become their electronic wallet and wait for the money to come in easily by betting. One attitude of Filipinos falling to gambling addiction is desperation. The mentality of a common gamblers always think that gambling is easy money. Gambling became a channel for Filipinos to earn extra income and to have flexibility with the necessities and gives them the pleasure to obtain their wants on a regular basis. The desire to experience thrills and entertaining atmosphere of the gambling scene shares a great factor to Filipinos as well. Huge amount of payouts boosts their social status and this will lure Filipinos further to continue playing up to the point where they will make time unconsciously and lose track of the important things that needs to be fulfilled. This would lead to uncontrollable gambling habit which makes them restless or shows irritability when they cut down or stop gambling. Online gambling is more convenient to Filipinos because they can easily place a bet wherever they are as long as they have internet. Features of Internet gambling may undermine the ability for gamblers to maintain control, such as its increased availability and accessibility, the ability to engage in high speed and uninterrupted play, convenient online payment methods, and gambling in private (Wardle, Moody, Griffiths, Orford, \& Volberg, 2011).

Evangelista \& Rivas (2018) expressed that,

There are currently no available data on the number of Filipinos addicted to online gambling activity, due to its mobile nature and the lack of legal jurisdiction in the country, however, psychologists and rehabilitation professionals believe that there are a number of Filipinos suffering silently.

\section{Effects of Gambling}

Gambling is not just about money, you may encounter having an unusual gambling behavior without being totally out of control. Gambling addiction also known as pathological gambling, compulsive gambling or gambling disorder is an impulse-control disorder. Problem gambling is any gambling behavior that disrupts your life. Problem gambling refers to the situation in which a person's gambling activity gives rise to harm to the individual player, and/or his or her family, and may extend into the community 
(Dickerson, McMillen, Hallebone, Volberg, Woolley. 1997, p.2.). From domestic violence, crimes, to addiction, family breakdowns, and even worse, suicides. These gamblingrelated harms are the negative impact from gambling on the health and well-being of every individual, families and the society itself. With all being said about the harmful acts of gambling, we can categorize them into three possible effects which is health, relationship, and resources.

In terms of health, harm relates to psychological effect (such as disgrace, guilt, shameful), mental health conditions (anxiety and depression) and in some cases includes suicidal behavior. This greatly harms the family and any close related person. Regarding relationships, it may very well result to break-ups or severance trust issues as well as reducing emotional and financial stability on households. You can easily see the signs of a certain individual if his or her mind is already corrupted with the effects caused by gambling by lack of focus and not having the energy to function or react. While resources generate harm through work place by underperforming and being unproductive resulting to failure in excellence. There is a further range of related consequences, some concerning material impacts such as housing instability, others concerning loss of opportunities and future well-being.

There's always that level of personal responsibility and personal accountability not partnered with the correct product information and social environment. While most people enjoy any form of gambling that provides them fund and entertainment, others may experience disruptive and addictive habit.

Gambling always sets up people for failure and giving shame on top of them when they do something that the machine, card tables, etc. are actually intentionally designed to do. Everyone has the consent to play, but at the same time, they are unaware of the mental manipulation. The perception that gambling can cause harm to gamblers and adversely impact society has led to the convergence of strong socio-political forces designed to reverse, restrict or moderate gambling activity in the community.

Over the past decade, the use of computers and the Internet has significantly altered the gambling landscape. With the innovation of modern technology, access to gambling activities can be achieved with a handful of gadgets of just by using the computer with a few strokes. With this phenomena, there could be a special kind of intelligence for thinking about risk and uncertainty. Many governments include considerations of harms related to Internet gambling in their legislative efforts. Nonetheless, the use of Internet gambling and its unique contribution to gambling-related problems is limited. Initial prevalence studies that included Internet gambling suggested that the rates of gambling problems are significantly higher in populations of online compared to landbased gamblers (Griffith, Wardle, Orford, Sproston, \& Erens, 2011). Gambling engagement is an important predictor of gambling-related harms or family failures. The overall aim of this research is to explore the influences to each gambler on how their 
thoughts became preoccupied to allow online gambling to be a part of their daily habit. With the collective effort in this study, this can administer strong analytical skills to some degree how we can reverse the losing mindset to a sense of control over uncertainty. Gambling is a matter of luck as they say, but some types of games doesn't require any luck but rather offer the opportunity to exercise skill and expertise, and this expertise can make them become very rich. By studying the way these gamblers think, this research can highly contribute a lot about how to prevent an individual suffer from online gambling addiction.

This study will focus on the emotional and psychological behavior of online gamblers and to determine the process and mechanisms that may lead them to gamble online. By using quantitative approach on gamblers, the research will help us measure their addiction and their craving to win on something. A few information from the country's regulation are also involve in this research to help us understand how online gambling companies operate and open markets in the Philippines. The majority of the study will revolve around the Philippines with at least 3 years of experience from online gambling. Lastly, the research will require survey to an individual with gambling experiences to explain further the overall cycle from the beginning up to the current status that results to online gambling behavior.

\section{METHOD}

The paradigm that will be used in this research is Positivism. Positivism strongly satisfies the qualities of doing research about this matter. It consists of verification and experimental studies as to how these huge and growing companies brand themselves to open a market on a specific country. We all know that gambling is mostly prohibited in many countries. With that being said, these companies portrayed the attitude of being ontological asking themselves how to things change over time.

Survey analysis is the most fundamental tool for all quantitative research methodologies and studies. Surveys are usually used to ask questions to a sample of respondents, using various types such as such as online polls, online surveys and paper questionnaires. The research used Survey on active gamblers around the Philippines. By means of carrying out survey research, a group of people can be asked with multiple survey questions, collect data from a pool of customers and analyze this collected data to produce numerical results. The approach is intended to be accessible to and informative for a broad audience.

The researcher will use cross-sectional survey for analytical purposes of data collection. A cross-sectional study can be helpful in determining how many people are affected by a condition and whether the frequency of the occurrence varies across groups or population characteristics (Hamed, 2015). 
In a cross-sectional study, the researcher measures the outcome and the exposures in the study participants at the same time. The participants in a cross-sectional study are just selected based on the inclusion and exclusion criteria set for the study. Once the participants have been selected for the study, the investigator follows the study to assess the exposure and the outcomes (Dermatol, 2016). This type of research can be used to describe characteristics that exist in a community, but not to determine causeand-effect relationships between different variables. Cross-sectional survey often allows the researcher to look at numerous characteristics at once and is used to look the prevailing characteristics in a given population.

In this research, the eligibility criteria in this study is that the participants should be residing in the Philippines. To calculate the sample size, we need to know what Level of confidence we will use and Margin of error that we can accept while the Estimated Proportion will be at default of 50\%. Using Cochran's formula to determine the sample size, a subset of 100 respondents will be given survey questions selected out of the entire population of the Philippines. To explain further, the researcher used a $15 \%$ margin of error that will give us 30 as the sample size following the formula above.

Sampling technique used for this study was purposive sampling, which is judgment sampling. The criteria for selecting the respondents are adults that are well experienced with online gambling residing within the Philippines. This involves a screening process where a series of questions are asked with their Gender, Age, Location, Education, Job Industry, Years of doing online gambling, bet frequency and Daily spending on online gambling.

A questionnaire is defined as a document containing questions and other types of items designed to solicit information appropriate to analysis (Babbie, 1990:377). Questionnaire is equally used in survey research, experiments and other modes of observation. Likert Scaling (Summative) design will be used to answer the questionnaire. It is the arrangement of opinions from extreme negative to extreme positive. According to McLeod (2014), Likert scale was devised in order to measure 'attitude' in a scientifically accepted and validated manner. Most Likert scales have five possible choices: two positive, two negative, and a neutral, or undecided. This, however, presents some problems. Thompson (2018) have expressed that a six-point scale forces choice, giving the researcher a better data, and, if at any point a neutral is desired, the "slightly agree" and "slightly disagree" can be averaged together.

The scale will be as follows:

$1=$ Strongly Disagree

2 = Disagree

$3=$ Slightly Disagree

4 = Slightly Agree 
$5=$ Agree

6 = Strongly Agree

In order to have our research to be of any use, the data must possess certain properties like reliability and validity that ensure unbiased, accurate, and authentic results. Reliability and validity are concepts used to evaluate the quality of research. They indicate how well a method, technique or test measures something. Tavakol \& Dennick (2011) also supported that these are important concepts in modern research, as they are used for enhancing the accuracy of the assessment and evaluation of a research work Reliability is referred to the stability of findings, whereas validity is represented the truthfulness of findings (Altheide \& Johnson, 1994).

Test-retest reliability is a measure of reliability obtained by administering the same test twice over a period of time to a group of individuals. The scores from Time 1 and Time 2 can then be correlated in order to evaluate the test for stability over time (Phelan \& Wren, 2006).

For measuring reliability for two tests, the researcher will use Cronbach's Apha. According to Laerd Statistics (n.d), Cronbach's alpha is the most common measure of internal consistency ("reliability"). It is most commonly used when you have multiple Likert questions in a survey/questionnaire that form a scale and you wish to determine if the scale is reliable.

The data analysis that will be used in this research is Multiple Regression Analysis. Multiple regression generally explains the relationship between multiple independent or predictor variables and one dependent or criterion variable.

According to Salkind (2010),

Multiple regression is a general and flexible statistical method for analyzing associations between two or more independent variables and a single dependent variable. As a general statistical technique, multiple regression can be employed to predict values of a particular variable based on knowledge of its association with known values of other variables, and it can be used to test scientific hypotheses about whether and to what extent certain independent variables explain variation in a dependent variable of interest.

The multiple regression equation explained above takes the following form:

$$
\mathrm{Y}=\mathbf{a}+\mathbf{b} \mathbf{X 1}+\mathbf{b} \mathbf{X} 2+\mathbf{b} \mathrm{X} 3
$$

Multiple Regressions are a method to predict the dependent variable with the help of two or more independent variables. While running this analysis, the main purpose of the researcher is to find out the relationship between the dependent variable and the independent variables. 
Variable Operationalization will consist 4 variables. In this research, there are 2 independent variables to be used. Consumer Attitude and Government Regulations are the independent variables and assumed to have a direct effect on the dependent variable. An intervening variable which is Promotional Ads is included as it follows the independent variables (x1 \& x2) but precedes the dependent variable. And lastly, Online Gambling Behavior will be the dependent variable as it will be tested and measured.

The study will take in the Philippines as there is a growing number of online gaming companies for the past few years, both legal \& illegal with weak jurisdictions. Criteria of the respondents in the research is people who do online gambling. These respondents are residing within the Philippines. Respondents required to fill the name, age, gender, and education background. Besides the criteria of respondents, experience is also important to understand the meaning of the survey.

\section{RESULT AND DISCUSSION}

Gambling in the Philippines has been present since the sixteenth century, and is still prevalent in the country today. Currently, it takes on various legal and illegal forms found almost all over the archipelago. If the gambling casinos are bad, the online gambling stations are worse. Online gambling stations are Internet cafes devoted to gambling games. Online gambling has been increasing in popularity, in fact, Barcelo \& Ramos-Araneta (2019) stated that the online gambling industry is now the second biggest demand driver for office space in the Philippines. Online gambling can be accessible whether in the office, residential communities, or even at school. With the use of Internet, you can start playing your game of chance. Because gambling can be a habit, many students get addicted to gambling. Youngsters end up spending their time at these stations, instead of at home or school. While for adults, it can lead to empty savings, huge debts, or worse - life threatening future. History reveals that gambling has destroyed families, careers, and even lives. One visible problem who's always tied-up with gambling is crime. Online gambling is an immediate, nationwide threat to the wellbeing of the Filipino youth.

Table 1: Demographic Profile

\begin{tabular}{|l|l|l|l|}
\hline $\begin{array}{l}\text { Demographic } \\
\text { Factors }\end{array}$ & & Frequency & Percentage \\
\hline \multirow{3}{*}{ Gender } & Female & 8 & $8.0 \%$ \\
\cline { 2 - 4 } & Male & 92 & $92.0 \%$ \\
\hline \multirow{3}{*}{ Age } & $20-25$ & 2 & $2.0 \%$ \\
\cline { 2 - 4 } & $26-30$ & 21 & $21.0 \%$ \\
\cline { 2 - 4 } & $31-35$ & 75 & $75.0 \%$ \\
\cline { 2 - 4 } & $36-40$ & 2 & $2.0 \%$ \\
\hline
\end{tabular}




\begin{tabular}{|l|l|l|l|}
\multirow{5}{*}{ Location } & Makati City & 37 & $37.0 \%$ \\
\cline { 2 - 4 } & Mandaluyong City & 17 & $17.0 \%$ \\
\cline { 2 - 4 } Education & Paranaque City & 14 & $14.0 \%$ \\
\cline { 2 - 4 } & Quezon City & 27 & $27.0 \%$ \\
\cline { 2 - 4 } & San Juan City & 5 & $5.0 \%$ \\
\hline \multirow{5}{*}{ Job Industry } & Bachelor's Degree & 85 & $85.0 \%$ \\
\cline { 2 - 4 } & Diploma & 5 & $5.0 \%$ \\
\cline { 2 - 4 } & Master's Degree & 10 & $10.0 \%$ \\
\hline & $\begin{array}{l}\text { Accounting \& } \\
\text { Legal }\end{array}$ & 7 & $7.0 \%$ \\
\cline { 2 - 4 } & Business Services & 30 & $30.0 \%$ \\
\cline { 2 - 4 } & Education & 10 & $10.0 \%$ \\
\cline { 2 - 4 } & I.T & 17 & $3.0 \%$ \\
\cline { 2 - 4 } & Others & 33 & $3.0 \%$ \\
\cline { 2 - 4 } & Retail & 3 & \\
\hline
\end{tabular}

Based on the table above, the age of respondents consists of 4 groups, including 2-25 years old, 26-30 years old, 31-35 years old, and lastly, 36-40 years of age. The age group was dominated by 31-35 years of age with 75\%, followed by $26-30$ years of age by respondents with 21\%. Both 20-25 \& 36-40 years of age shared 2\% each. With regards to Gender, majority of the respondents were male with $92 \%$ while female respondents only recorded $8 \%$. Meanwhile, the location was almost shared evenly except for San Juan City which received the least number of respondents with only 5\%. Makati \& Quezon City recorded the highest respectively with 37\% \& 27\% while Mandaluyong \& Paranaque City had $17 \%$ \& 14\% respectively. The educational background was also included in the screening test, and with no surprise, High School graduates had zero respondents. Majority of the respondents finished their Bachelor's degree with 85\%, while those with Master's degree had 10\% respondents. Recording the least are those with Diploma covering 5\% only of the total respondents. Lastly, we collected their current job industry where they get their income or savings to use for their online gambling activities. Coming in at first are those working outside the categories above or Others with 37\%, while Business services had 30\% responders. I.T workers collected the third highest with $17 \%$ while Education \& Accounting \& Legal shared the fourth \& fifth spot with $10 \%$ and $7 \%$ respectively. Those working at Retail industry had the lowest recording of respondents with only $3 \%$.

Table 2: Consumer Attitude (x1). Descriptive Analysis

\begin{tabular}{|l|l|l|l|}
\hline Variable & Dimension & Indicators & $\begin{array}{l}\text { Mean per } \\
\text { Item }\end{array}$ \\
\hline $\begin{array}{l}\text { Consumer } \\
\text { Attitude }\end{array}$ & $\begin{array}{l}\text { Economic } \\
\text { Motive }\end{array}$ & Money & 4.76 \\
\hline
\end{tabular}




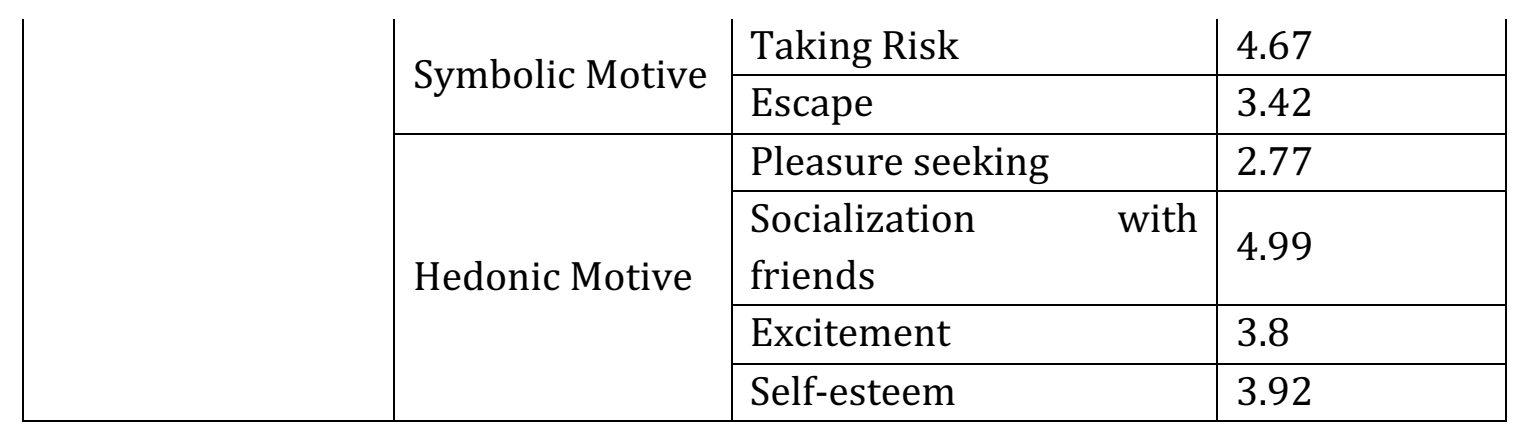

Table 3. Government Regulations (x2). Descriptive Analysis

\begin{tabular}{|l|l|l|l|}
\hline Variable & Dimension & Indicators & $\begin{array}{l}\text { Mean per } \\
\text { Item }\end{array}$ \\
\hline \multirow{5}{*}{ Government Regulations } & Oversee Operations & $\begin{array}{l}\text { Illegal Gambling } \\
\text { Activities }\end{array}$ & 2.31 \\
\cline { 2 - 4 } & Promote Tourism & $\begin{array}{l}\text { To License } \\
\text { Operations }\end{array}$ & 2.57 \\
\cline { 2 - 4 } & Investors & 2.4 \\
\cline { 2 - 4 } & Generate Funds & $\begin{array}{l}\text { Government } \\
\text { Development } \\
\text { Programs }\end{array}$ & 2.63 \\
\hline
\end{tabular}

Table 4. Promotional Ads (z1). Descriptive Analysis

\begin{tabular}{|c|c|c|c|}
\hline Variable & Dimension & Indicators & Mean \\
\hline \multirow{10}{*}{$\begin{array}{l}\text { Promotional } \\
\text { Ads }\end{array}$} & \multirow{4}{*}{ Attracting New Players } & Television & 1.27 \\
\hline & & Radio & 1.38 \\
\hline & & $\begin{array}{l}\text { Online } \\
\text { Advertisements }\end{array}$ & 5.17 \\
\hline & & $\begin{array}{l}\text { Land based } \\
\text { gambling outlets }\end{array}$ & 5.17 \\
\hline & \multirow[b]{2}{*}{$\begin{array}{l}\text { Increased Gambling (existing } \\
\text { players) }\end{array}$} & Word of mouth & 4.91 \\
\hline & & $\begin{array}{l}\text { Friends } \\
\text { Recommendation }\end{array}$ & 5.04 \\
\hline & \multirow{2}{*}{ Retained gamblers } & Reminders & 4.35 \\
\hline & & Free Bets & 4.87 \\
\hline & Attracting inactive players & Receiving Email & 5.46 \\
\hline & Causing longer gambling sessions & Bonuses & 5.46 \\
\hline
\end{tabular}




\begin{tabular}{|l|l|l|l|} 
& $\begin{array}{l}\text { Difficulty to } \\
\text { withdraw }\end{array}$ & 3.43 \\
\hline
\end{tabular}

Table 5. Online Gambling Behavior (y1). Descriptive Analysis

\begin{tabular}{|l|l|l|l|}
\hline Variable & Dimension & Indicators & Mean per item \\
\hline \multirow{4}{*}{$\begin{array}{l}\text { Online Gambling } \\
\text { Behavior }\end{array}$} & Easy Access & Convenience & 5.62 \\
\cline { 3 - 4 } & $\begin{array}{l}\text { Technological } \\
\text { Advancement }\end{array}$ & 5.60 \\
\cline { 3 - 4 } & Physical Comfort & 5.59 \\
\cline { 2 - 4 } & $\begin{array}{l}\text { Continuous } \\
\text { Gambling }\end{array}$ & Payout rates & 4.94 \\
\cline { 2 - 4 } & Products Offered & 5.38 \\
\hline
\end{tabular}

The table for Consumer Attitude table consist of 7 items in which they each have a 6point scale. Item 5 recorder the highest in relation to Socialization with friends with a mean of 4.99 while pleasure seeking collected the lowest average with 2.77 only. With that being said, majority of the respondents agree that online gambling is a highly recognized attitude when socializing with friends.

In the case of Government Regulation variable, it consists of 5 items with the same number of scale from $\mathrm{x} 1$ with 1-6. The respondents returned an average of 2.63 for Government Development programs which is also the highest amongst the 5 items while Illegal Gambling Activities returned the lowest mean from variable $\mathrm{x} 2$ with an average of 2.31 which is not that far from Illegal Gambling Activities.

Promotional Ads contains the most number of items with 11. Two items recorded the same average with 5.46 namely Receiving Email \& Bonuses. Both of these items have also recorded the highest among the others. Not far behind were Land Based Gambling Outlet \& Online Advertisements which also has the same average of 5.17. Radio and Television returned the lowest mean respectively with $1.38 \& 1.27$.

Variable Y received the most accurate returns from our respondents getting majority of the items greater the 5 as the mean. This clearly suggest that Online Gambling Behavior is relatively significant with Convenience, Technological Advancement, Physical Comfort, Payout rates \& Products offered.

Based on the data analysis, it showed that majority of the respondents are Male. This research focuses on active gamblers residing in the Philippines with an experience of online gambling. The respondents are dominated by individuals between $31-35$ years old. Most of the respondents are coming from Makati City, this tendency occurred because the most of the online gambling companies are operating on that same are, and a few in Quezon City. More than half of the respondents finished their bachelor's degree. Due to their achievement in College, these individuals have different career paths and 
almost showed evenly shared percentage in terms of their job industry. While majority are employed, it also shared and idea that they can provide enough money to use for their online gambling activity. Given that the location are greatly shared from Makati City \& Quezon City which has establishment office buildings for online gambling companies, it is also understandable that these individuals are more exposed to online gambling whether through word-of-mouth from their friends, or by simply noticing advertisements on land based gambling outlets. Perhaps that most intriguing part is that even though the highest recorded years of experiences towards online gambling ranges from 3-5 years, their daily spending for online gambling are less than 1,000 pesos only while only a few are manageable to spend $>10,000$ pesos a day for online gambling.

Meanwhile, in the descriptive behavior, the highest mean by variable was recorded to Online Gambling Behavior. The indicators satisfy the respondents to convince them answering around 4 to 6 in a 6-point scale, with 6 declaring as "strongly agree". Consumer attitude had a variable mean of 4.04 where socialization with friends recorded the highest average by item with 4.99 . This highly suggest that the pre-act to online gambling is highly influenced by their friends to be more socialized. This of course are follow by Money \& taking risk as both of these indicators are significantly proportion with any types of gambling.

\section{CONCLUSION}

In conclusion, this study has investigated the impact of Consumer Attitude \& Government Regulation towards Online Gambling Behavior. The study was performed with quantitative method and come up with these findings:

1. Consumer Attitude and Government Regulations combined have significant influence towards Online Gambling Behavior.

2. Consumer attitude alone doesn't offer significant impact towards online gambling behavior.

3. Every increase of activity from Government Regulation, it will also increase the activity towards Online Gambling Behavior.

4. Promotional Ads has an opposite impact towards Online Gambling Behavior.

In this research, combined consumer attitude and government regulations are actually the mediating variables towards online gambling behavior. However, the intervening variable which is promotional ads shows that it has an opposite impact towards online gambling behavior based from the respondents' return of survey. Therefore, it indicates that both consumer attitude and government regulations combined has great impact towards online gambling behavior. 
The study can be useful for the development of the social behavior on business ethics \& marketing communications, particularly the measurement of consumer behavior \& promotional ads on how to be effective. This study also helped to bring out interesting new topics to be studied, namely the importance of government regulations.

The limitation of this research covers the respondents of Filipinos since the study is highlighted or focused in the Philippines. From the research, many respondents answered that it is too convenient for them to do online gambling and they can easily access it anywhere they want and anytime they prefer because of its technological advancement and physical comfort. Land based gambling have been an entertaining sight from the past, but with the fast growing of technology, gambling has been consistent to be part of it by becoming accessible with newly products that are being offered. To prevent causing gambling harm whether financial unstable or personal debts, the government should act more \& come up with more restriction order in the Philippines before it becomes uncontrollable just like the evolution of technology.

\section{REFERENCES}

Abbott, M. W., \& Volberg, R. A. (1999). A reply to Gambino's "An epidemiologic note on verification bias: Implications for estimation of rates". Journal of Gambling Studies, 15, 233-242

Babbie, E. (2010) The practice of social research 12th edition. Wadsworth:Belmont.

Bond, S., Jorm, A., Miller, H., Rodda, S., Reavley, N., Kelly, C., Kitchener, B. (2016). How a concerned family member, friend or member of the public can help someone with gambling problems?

Boreham, P., Dickerson, M., \& Harley, B. (1996). What are the social costs of gambling: The case of the Queensland machine gaming industry? Australian Journal of Social Issues, 31, 425-44.

Dickerson, M. McMillen, J. Hallebone, E. Volberg, T. Woolley, R. (1997): Definition and incidence of problem gambling, including the socio-economic distribution of gamblers. Melbourne, Victoria: Victorian Casino and Gaming Authority

Dowling, N. (2014). The impact of gambling problems on families

Dymond, S., Roche, B. (2010). The Impact of Derived Relational Responding on Gambling Behavior

European Commission. (2011). Green paper on on-line gambling in the Internal Market.

Fisher, R.A. (1948). Biometry: Biometrics, 4, 217-219. 


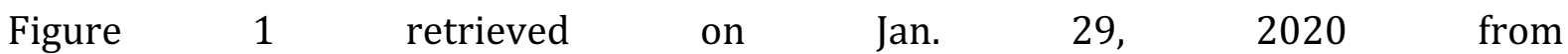
https://www.statista.com/statistics/253416/global-gambling-market-grosswin/

Gainsburry, S. (2015). Online Gambling Addiction: The relationship between internet gambling and disordered gambling.

Gainsbury, S., Wood, R., Russell, A., Hing, N., \& Blaszczynski, A. (2012). A digital revolution: Comparison of demographic profiles, attitudes and gambling behaviour of Internet and non-Internet gamblers. Computers in Human Behaviour, 28, 1388-1398.

Goodman, R. (1995). The luck business: The devastating consequences and broken promises of America's gambling explosion.

Gory, Jay (2020). What are the laws about gambling in the Philippines? Retrieved from http://www.superbious.com/Legal/article_308_What-are-the-laws-aboutgambling-in-the-Philippines.html

He, B., Johansson, D. (2014). Sustainable Gambling Business

Hedberg, J., Liikanen, J. (2012). "If you're gonna play the game, you gotta learn to play it right" Relationship marketing in the online gambling industry.

Holdsworth, L., Nuske, E., Tiyce, M. Hing, N. (2013). Impacts of gambling problems on partners: partners' interpretations

Holtgraves, T. (2009). Gambling, Gambling activities, and Gambling problems

McCormick, A. V. \& Cohen, I. M. (2007). A review of online gambling literature.

Moscovici, S. (1984). The phenomenon of social representations. In R. Farr and S. Moscovici (Eds), Social Representations(pp.3-69)

Parke, J., Parke, A., \& Blaszczynski, A. (2016). Key issues in product-based harm minimization.

Platz, L., Millar, M. (2001). Gambling in the context of other recreation activity: A quantitative comparison of casual and pathological student gamblers.

Polit, D. F., \& Hungler, B. P. (1999). Nursing research: principles and methods. Philadelphia: JB Lippincott Company.

Psychology Today. (2019). Gambling Disorder (Compulsive Gambling, Pathological Gambling). Retrieved from: https://www.psychologytoday.com/intl/conditions/gambling-disordercompulsive-gambling-pathological-gambling

Sabbadin, D. (2017). Business of Gambling: impact on Italian economy, policies and regulation of the phenomenon

Sand, B. (2017). Gambling Regulation - Global Developments 2017 
Skinner, H, Biscope, S, Murray, M., Korn, D. (2004). Dares to addiction: Youth definitions and perspectives on gambling

Wardle, H., Moody, A., Griffiths, M., Orford, J., \& Volberg, R. (2011). Defining the online gambler and patterns of behavior integration: Evidence from the British Gambling Prevalence Survey 2010. International Gambling Studies, 11(3), 339356.

Williams, R., Connolly, D. (2006). MATHEMATICS OF GAMBLING 